\title{
Guideline update for the performance of fusion procedures for degenerative disease of the lumbar spine. Part 7: Lumbar fusion for intractable low-back pain without stenosis or spondylolisthesis
}

\author{
Jason C. Eck, D.O., M.S., ${ }^{1}$ Alok Sharan, M.D., ${ }^{2}$ Zoher Ghogawala, M.D., ${ }^{3}$ \\ Daniel K. Resnick, M.D. ${ }^{4}$ William C. Watters III, M.D., ${ }^{5}$ Praveen V. Mummaneni, M.D., ${ }^{6}$ \\ Andrew T. Dailey, M.D. ${ }^{7}$ Tanvir F. Choudhri, M.D. ${ }^{8}$ Michael W. Groff, M.D. ${ }^{9}$ \\ Jeffrey C. Wang, M.D., ${ }^{10}$ Sanjay S. Dhall, M.D., ${ }^{6}$ and Michael G. Kaiser, M.D. ${ }^{11}$ \\ ${ }^{I}$ Center for Sports Medicine and Orthopaedics, Chattanooga, Tennessee; ${ }^{2}$ Department of Orthopaedic Surgery, \\ Montefiore Medical Center, Albert Einstein College of Medicine, Bronx, New York; ${ }^{3}$ Alan and Jacqueline \\ Stuart Spine Research Center, Department of Neurosurgery, Lahey Clinic, Burlington, and Tufts University \\ School of Medicine, Boston, Massachusetts; ${ }^{4}$ Department of Neurosurgery, University of Wisconsin, Madison, \\ Wisconsin; ${ }^{5}$ Bone and Joint Clinic of Houston, Houston, Texas; ${ }^{6}$ Department of Neurological Surgery, \\ University of California, San Francisco, California; ${ }^{7}$ Department of Neurosurgery, University of Utah, \\ Salt Lake City, Utah; ${ }^{8}$ Department of Neurosurgery, Icahn School of Medicine at Mount Sinai, New York, \\ New York; ${ }^{9}$ Department of Spinal Neurosurgery, Brigham and Women's Hospital, Boston, Massachusetts; \\ ${ }^{10}$ Department of Orthopaedic Surgery, Keck School of Medicine, University of Southern California, Los \\ Angeles, California; and "Department of Neurosurgery, Columbia University, New York, New York
}

\begin{abstract}
Establishing an appropriate treatment strategy for patients presenting with low-back pain, in the absence of stenosis or spondylolisthesis, remains a controversial subject. Inherent to this situation is often an inability to adequately identify the source of low-back pain to justify various treatment recommendations, such as lumbar fusion. The current evidence does not identify a single best treatment alternative for these patients. Based on a number of prospective, randomized trials, comparable outcomes, for patients presenting with 1- or 2-level degenerative disc disease, have been demonstrated following either lumbar fusion or a comprehensive rehabilitation program with a cognitive element. Limited access to such comprehensive rehabilitative programs may prove problematic when pursuing this alternative. For patients whose pain is refractory to conservative care, lumbar fusion is recommended. Limitations of these studies preclude the ability to present the most robust recommendation in support of lumbar fusion. A number of lesser-quality studies, primarily case series, also support the use of lumbar fusion in this patient population. (http://thejns.org/doi/abs/10.3171/2014.4.SPINE14270)
\end{abstract}

KEY WORDS $\quad$ low-back pain $\bullet$
practice guidelines $\quad \bullet \quad$ lumbar spine

\section{Recommendations}

There is no evidence that conflicts with the previous recommendations published in the original version of the Lumbar Fusion Guidelines ("Guidelines for the performance of fusion procedures for degenerative disease of the lumbar spine").

\section{Grade B}

Lumbar fusion or a comprehensive rehabilitation program incorporating cognitive therapy are recommended as treatment alternatives for patients with chronic lowback pain that is refractory to traditional conservative

Abbreviations used in this paper: ODI = Oswestry Disability Index; SF-36 = 36-Item Short Form Health Survey; VAS = visual analog scale. treatment, such as physical therapy, and is due to 1- or 2-level degenerative disc disease without stenosis or spondylolisthesis (multiple Level II studies).

It is recommended that lumbar fusion be performed for patients whose low-back pain is refractory to conservative treatment (physical therapy or other nonoperative measures) and is due to 1- or 2-level degenerative disc disease without stenosis or spondylolisthesis (multiple Level II studies).

\section{Rationale}

Lumbar fusion has become an accepted treatment alternative for low-back pain associated with stenosis and spondylolisthesis. There is a growing body of evidence including that from the Spine Patient Outcomes Research Trial (SPORT) that consistently demonstrates improved 


\section{Part 7: Fusion for pain without stenosis or spondylolisthesis}

clinical outcomes with lumbar fusions for patients who fail conservative care. . $^{1,32}$

Chronic low-back pain associated with lumbar spondylosis, in the absence of stenosis or spondylolisthesis, is a common clinical problem; however, the optimal treatment strategy for this condition remains a controversial topic. Part of this uncertainty results, in many cases, from the inability to accurately determine the actual source of pain. The lack of specificity regarding the changes identified on MRI only adds to the uncertainty when formulating a management strategy. There are many conservative and several surgical treatment options available for the treatment of chronic back pain; however, consistent evidence of superior efficacy of one approach over another is lacking. When conservative measures fail to improve the patient's pain, lumbar fusion is often considered an appropriate treatment alternative. The high costs, risk of serious complications, and lack of consistent supporting evidence raise questions as to whether fusion for lumbar spondylosis is cost-effective and will lead to functional recovery. The purpose of this review is to evaluate the published literature regarding the use of lumbar fusion for the treatment of patients with intractable low-back pain without stenosis or spondylolisthesis.

\section{Literature Search}

The database of the National Library of Medicine was searched for articles published between July 2003 and December 2011 using the following search terms: ("Low Back Pain"[MeSH] OR "low back pain"[title]) AND ((((“Lumbosacral Region”[MeSH] OR "Lumbar Vertebrae"[MeSH]) AND "Spinal Fusion"[MeSH]) OR "lumbar fusion"[All Fields] OR ("lumbar"[MeSH] AND "fusion"[title])) AND ("Treatment Outcome"[MeSH] OR "Patient Satisfaction"[MeSH] OR "functional outcome" [All Fields] OR "functional outcomes"[All Fields] OR "outcome"[title] OR “outcomes"[title] OR “clinical outcome"[All Fields] OR "clinical outcomes"[All Fields]) AND ((“2003”[PDAT]: “3000”[PDAT]) AND "humans" [MeSH] AND English[lang])). Search results were limited to human studies, English language, and patients between the ages of 18 and 65. Duplicates, technical notes, reviews, and other publications that did not describe the use of lumbar fusion for patients with low-back pain without stenosis or spondylolisthesis were discarded. The bibliographies of the selected articles were inspected and additional relevant papers were identified. Three clinical series and one systematic review that contributed to the guideline formulation are described in Table 1 . The remaining references provided additional background information and are included in the bibliography.

\section{Scientific Foundation}

A review of the Cochrane database failed to identify a randomized, controlled trial investigating the utility of lumbar fusion for the treatment of low-back pain due to spondylosis. ${ }^{19}$ Two subsequent randomized trials were summarized in the original version of the Lumbar Fusion Guidelines. ${ }^{29}$ Fritzell et al. performed a randomized, controlled, multicenter trial of patients presenting with back pain presumably due to lumbar spondylosis. A total of 294 patients were randomized to one of 3 surgical groups or to physical therapy. ${ }^{16}$ At 2 years' follow-up, 289 (98\%) of the initial 294 patients remained in the study, but 25 had changed treatment groups. Each of the surgical groups achieved better clinical outcomes than the conservatively treated cohort. Back pain was reduced by $33 \%$ in the surgical groups versus $7 \%$ in the control group $(p=0.0002)$. The Oswestry Disability Index (ODI) score improved by $25 \%$ in the surgically treated patients and only $6 \%$ in the controls $(\mathrm{p}=0.015)$. The return-to-work rate was $36 \%$ in the surgically treated patients versus $13 \%$ in the controls $(\mathrm{p}=0.002)$. The authors concluded that lumbar fusion was a more effective treatment option for patients with chronic low-back pain after failure of conservative care than traditional nonsurgical treatment. Limitations of this study included a lack of well-defined conservative treatment group and patient crossover. This study provides Level II evidence in favor of lumbar fusion over traditional nonoperative treatment for patients with low-back pain.

In a smaller study of 64 patients, Brox et al. compared instrumented fusion versus physical therapy with cognitive exercises in patients presenting with chronic low-back pain and spondylosis at L4-5 and/or L5-S1 on plain radiographs. ${ }^{7}$ Patients were followed for 1 year with a $97 \%$ follow-up rate. The main outcomes measure was the ODI. The mean difference between the groups was 2.3 (not significant, $p=0.33$ ). Limitations of the study included a small sample size and wide variation between patients. This study provides Level II data for the equivalence between lumbar fusion and physical and cognitive therapy for patients with low-back pain.

There have been 3 prospective, randomized trials comparing lumbar fusion to conservative treatment and one systematic review of the literature since the publication of the original guidelines, , $^{6,14,26}$

Brox et al. performed a prospective, randomized study comparing the clinical results of lumbar fusion versus cognitive intervention and exercises in patients with chronic back pain following surgery for lumbar disc herniation. ${ }^{6}$ Inclusion criteria consisted of age 25-60 years, at least 1 year of low-back pain following a lumbar discectomy, and lumbar disc degeneration at L4-5 and/or L5-S1 on plain radiographs. Patients were excluded if there was evidence of spinal stenosis, widespread myofascial pain, recurrent disc herniations, inflammatory disease, fracture, previous lumbar fusion, and/or psychiatric disease. Patients were randomized to either posterolateral instrumented fusion with autologous bone graft or cognitive intervention and exercises. The rehabilitation program lasted approximately 25 hours per week for 3 weeks. Patients were given information on the relevant anatomy and the mechanisms of pain. They were instructed that they could not harm themselves during routine activities of daily living. The specific exercise program was tailored to the individual patient. The ODI was used as the primary outcome measure. Secondary measures included the VAS, medication usage, General Function Score, Global Back Disability Questionnaire, work status, and the Prolo scale. The General Function Score consists of 9 questions used to measure back-related disability in activities of daily living and has been previously validated. ${ }^{23}$ 
TABLE 1: Lumbar fusion versus conservative treatment for chronic low-back pain: summary of evidence*

\begin{tabular}{|c|c|c|c|}
\hline $\begin{array}{c}\text { Authors \& } \\
\text { Year }\end{array}$ & $\begin{array}{l}\text { Level of } \\
\text { Evidence }\end{array}$ & Description & Comments \\
\hline $\begin{array}{l}\text { Fritzell et } \\
\quad \text { al., } 2001\end{array}$ & II & $\begin{array}{l}\text { Prospective, randomized, controlled, multicenter trial. } 294 \text { pts w/ LBP randomized } \\
\text { to } 1 \text { of } 3 \text { surgical groups or PT (controls). At } 2 \text {-yr follow-up } 289(98 \%) \text { of the } \\
\text { initial } 294 \text { pts remained, but } 25 \text { had changed treatment groups. Each surgical } \\
\text { group had improved clinical outcomes compared to the PT cohort. Back pain } \\
\text { was reduced by } 33 \% \text { in surgical groups vs } 7 \% \text { in controls ( } p=0.0002) \text {. ODI } \\
\text { improved } 25 \% \text { in the surgical groups vs } 6 \% \text { in controls ( } p=0.015) \text {. Return- } \\
\text { to-work rate was } 36 \% \text { in the surgical groups vs } 13 \% \text { in controls }(p=0.002) \text {. } \\
\text { Authors concluded that lumbar fusion was more effective than traditional } \\
\text { nonsurgical treatment for pts w/ chronic LBP after failure of conservative care. }\end{array}$ & $\begin{array}{l}\text { Limitations of this study include a lack of } \\
\text { a well-defined conservative treatment } \\
\text { group \& patient crossover. This study } \\
\text { provides Level II evidence in favor of } \\
\text { lumbar fusion over traditional nonop- } \\
\text { erative treatment for pts w/ LBP. }\end{array}$ \\
\hline $\begin{array}{l}\text { Brox et al., } \\
2003\end{array}$ & II & $\begin{array}{l}\text { Prospective, randomized trial involving } 64 \text { pts \& comparing instrumented fusion } \\
\text { vs PT w/ cognitive exercises for chronic LBP. Pts were followed for } 1 \mathrm{yr} \text { w/ a } \\
97 \% \text { follow-up rate. Outcomes measured w/ ODI. Mean difference btwn the } \\
\text { groups was } 2.3 \text { (NS, } p=0.33 \text { ). }\end{array}$ & $\begin{array}{l}\text { Limitations of the study include a small } \\
\text { sample size \& wide variation btwn pts. } \\
\text { This study provides Level II data for } \\
\text { equivalence btwn lumbar fusion \& PT } \\
\text { w/ cognitive therapy for pts w/ LBP. }\end{array}$ \\
\hline $\begin{array}{r}\text { Fairbank et } \\
\text { al., } 2005\end{array}$ & II & $\begin{array}{l}\text { Prospective, randomized, multicenter trial. Outcome measures were the ODI \& } \\
\text { the shuttle walking test. Secondary outcomes included the SF-36, psychologi- } \\
\text { cal assessment, complications, \& work status. Pts evaluated at baseline \& at } \\
6,12, \& 24 \text { mos. Lumbar fusion technique not defined \& left to surgeon prefer- } \\
\text { ence. Intensive rehabilitation program consisted of education \& exercises } \\
5 \text { days a wk for } 3 \text { wks. Cognitive behavior therapy helped identify \& over- } \\
\text { come fears \& unhelpful beliefs. } 339 \text { pts randomized across } 15 \text { centers. ODI } \\
\text { improved from } 46.5 \text { to } 34.0 \text { in the surgical group vs } 44.8 \text { to } 36.1 \text { for control } \\
\text { group. Improvement in surgical cohort was significant compared to the reha- } \\
\text { bilitation group ( } p=0.045 \text { ). Shuttle walking test also improved in both groups, } \\
\text { but there were no significant differences. There were no statistically significant } \\
\text { differences btwn the } 2 \text { groups in any of the secondary outcome measures. }\end{array}$ & $\begin{array}{l}\text { Limitations of this study include a } 20 \% \\
\text { loss to follow-up at } 24 \text { mos \& } 28 \% \\
\text { crossover from rehabilitation to } \\
\text { surgery. The clinical significance of the } \\
\text { difference in ODI scores is unclear, } \\
\text { especially given the failure to observe } \\
\text { a relevant difference in the other } \\
\text { outcome measures. Based on these } \\
\text { limitations, the study was downgraded } \\
\text { to Level II evidence due to lack of } \\
\text { benefit of lumbar fusion over intensive } \\
\text { rehabilitation. }\end{array}$ \\
\hline $\begin{array}{l}\text { Brox et al., } \\
\quad 2006\end{array}$ & II & $\begin{array}{l}\text { Prospective, randomized study comparing lumbar fusion vs cognitive interven- } \\
\text { tion \& exercises in pts w/ chronic back pain following surgery for lumbar disc } \\
\text { herniation. Randomized to posterolateral instrumented fusion w/ autologous } \\
\text { bone graft or cognitive intervention \& exercises. Rehabilitation lasted approxi- } \\
\text { mately } 25 \text { hrs per wk for } 3 \text { wks. ODI was primary outcome measure. Second- } \\
\text { ary measures included VAS, medication usage, General Function Score, } \\
\text { Global Back Disability Questionnaire, work status, \& the Prolo Scale. Final } \\
\text { study included } 60 \text { pts, } 29 \text { randomized to fusion \& } 31 \text { to control. } 97 \% \text { follow-up } \\
\text { rate at } 1 \mathrm{yr} \text {, w/ } 6 \text { pts crossing over from surgery to the conservative treatment } \\
\text { cohort \& } 2 \text { pts in the conservative treatment group undergoing surgery. ODI } \\
\text { significantly improved in both groups, from } 47.0 \text { to } 38.1 \text { for fusion \& from } 45.1 \\
\text { to } 32.3 \text { for control ( } p=0.001 \text { ). No significant difference btwn groups at final } \\
\text { follow-up. }\end{array}$ & $\begin{array}{l}\text { Limitations of this study include a } \\
\text { small sample size despite the power } \\
\text { analysis, a relatively brief follow-up } \\
\text { period, \& the study of a small subset } \\
\text { of pts w/ chronic back pain who had } \\
\text { a previous lumbar discectomy. The } \\
\text { authors concluded that either treatment } \\
\text { alternative may be considered for pts } \\
\text { presenting w/ chronic LBP following } \\
\text { discectomy. Based on these limitations, } \\
\text { this study was downgraded to Level II } \\
\text { evidence supporting the use of either } \\
\text { lumbar fusion or intensive rehabilitation } \\
\text { w/ cognitive therapy for the treatment } \\
\text { of pts w/ chronic LBP w/out stenosis or } \\
\text { spondylolisthesis. }\end{array}$ \\
\hline $\begin{array}{l}\text { Ohtori et } \\
\text { al., } 2011\end{array}$ & ॥ & $\begin{array}{l}\text { Prospective study randomizing pts w/ discogenic LBP into surgical vs nonsurgi- } \\
\text { cal treatment groups. } 41 \text { pts w/ MRI evidence of disc degeneration at L4-5 or } \\
\text { L5-S1 \& pain provocation on discography w/ pain relief w/ discoblock. Surgery } \\
\text { consisted of ALIF unless there was difficulty w/ anterior vessels, in which } \\
\text { case a posterolateral instrumented fusion was performed. Nonsurgical control } \\
\text { included daily walking \& exercises following individual instruction. Outcomes } \\
\text { measures included VAS, ODI, \& JOA score. Subjective outcomes were } \\
\text { graded according to the NASS Low Back Outcome Instrument. Radiographic } \\
\text { evaluation of fusion was performed w/ AP radiographs \& CT scan by } 3 \text { blinded } \\
\text { observers. Data were compared preoperatively \& at } 1 \text { \& } 2 \text { yrs. All pts had solid } \\
\text { arthrodesis. Each of the outcomes measures was significantly better for the } \\
\text { surgical groups at } 2 \text { yrs as compared to the nonoperative group }(p<0.05) \text {. }\end{array}$ & $\begin{array}{l}\text { Limitations of the study include a small } \\
\text { sample size \& inconsistency in the } \\
\text { type of surgery performed. This study } \\
\text { provides Level Il evidence in favor of } \\
\text { surgery over walking \& exercises in pts } \\
\text { w/ chronic discogenic LBP. }\end{array}$ \\
\hline
\end{tabular}

(continued) 
Part 7: Fusion for pain without stenosis or spondylolisthesis

TABLE 1: Lumbar fusion versus conservative treatment for chronic low-back pain: summary of evidence* (continued)

\begin{tabular}{|c|c|c|c|}
\hline $\begin{array}{c}\text { Authors \& } \\
\text { Year }\end{array}$ & $\begin{array}{l}\text { Level of } \\
\text { Evidence }\end{array}$ & Description & Comments \\
\hline $\begin{array}{c}\text { Chou et al., } \\
2009\end{array}$ & II & $\begin{array}{l}\text { Systematic review of the literature to assess risks \& benefits of surgical treat- } \\
\text { ment of back pain. } 1449 \text { citations were reviewed, which led to a review of } 24 \\
\text { full-text articles on surgery for LBP for degenerative disorders, } 4 \text { of which } \\
\text { compared surgery to nonsurgical therapy. Guidelines suggested fusion was } \\
\text { no more effective than an intensive rehabilitation program, but fusion was } \\
\text { associated w/ moderate benefits as compared to traditional conservative } \\
\text { treatment options. }\end{array}$ & $\begin{array}{l}\text { This systematic review provides Level II } \\
\text { evidence for the equivalence of surgery } \\
\text { to an intensive rehabilitation program \& } \\
\text { moderate benefits of surgery over tradi- } \\
\text { tional nonoperative treatment options. }\end{array}$ \\
\hline
\end{tabular}

* $\mathrm{ALIF}=$ anterior lumbar interbody fusion; $\mathrm{AP}=$ anteroposterior; JOA = Japanese Orthopaedic Association; LBP = low-back pain; NASS = North American Spine Society; NS = not significant; ODI = Oswestry Disability Index; PT = physical therapy; pts = patients; SF-36 = 36-Item Short Form Health Survey; VAS = visual analog scale.

The authors initially performed a pilot study to determine the required sample size to demonstrate statistical significance. The final study consisted of 60 patients, 29 randomized to fusion and 31 receiving cognitive intervention and exercises. The percentage of male patients was significantly lower in the surgery group (38\%) than in the cognitive treatment and exercise group $(64 \%)(\mathrm{p}=0.04)$. There was a 97\% follow-up rate at one-year, with 6 patients crossing over from surgery to the conservative cohort and 2 patients in the conservative treatment group undergoing surgery. The mean ODI scores improved significantly in both groups (from 47.0 to 38.1 in the fusion group and from 45.1 to 32.3 in the conservative treatment group, $\mathrm{p}=$ 0.001). There was no significant difference between the 2 groups at final follow-up. Limitations of this study included a small sample size despite the power analysis, a relatively brief follow-up period, and the study of a small subset of patients with chronic back pain who had a previous lumbar discectomy. The authors concluded that either treatment alternative may be considered for patients presenting with chronic low-back pain following discectomy. Based on these limitations this study was downgraded to Level II evidence in supporting the use of either lumbar fusion or intensive rehabilitation with cognitive therapy for the treatment of patients with chronic low-back pain without stenosis or spondylolisthesis.

A large, prospective, randomized, multicenter trial was performed by Fairbank et al. to assess the effectiveness of spinal fusion versus an intensive rehabilitation program for patients with chronic low-back pain. ${ }^{14}$ All patients were between 18 and 55 years of age and had at least a 1-year history of low-back pain. Exclusion criteria consisted of infection, inflammatory disease, tumor, fracture, psychiatric disorders, pregnancy, and previous spinal fusion. Outcome measures were the ODI and the shuttle walking test. ${ }^{31}$ Secondary outcomes included the 36-Item Short Form Health Survey (SF-36), psychological assessment, complications, and work status. Patients were evaluated at baseline and after 6,12 , and 24 months. The technique of the lumbar fusion was not defined and was left to surgeon preference. The intensive rehabilitation program consisted of education and exercises 5 days each week for 3 consecutive weeks. The program was individually tailored to each patient and modified based on the patient's response. Cognitive behavior therapy was also included to help identify and overcome fears and unhelpful beliefs. This program educated patients on their anatomy and causes of pain and encouraged them to perform normal activities of daily living that would not cause them harm. ${ }^{17}$

The study population consisted of 339 patients randomized across 15 different centers. There were no significant baseline differences between the 2 cohorts. A significant crossover rate was observed in the conservatively treated patients. Forty-eight $(28 \%)$ of the patients randomized to the intensive rehabilitation group eventually had surgery; however, only 7 (4\%) of the patients randomized to surgery were treated with rehabilitation alone. There were 19 surgical complications, of which 11 required additional surgery. There were no complications attributed to the rehabilitation program. The mean ODI scores improved from 46.5 to 34.0 in the surgical group versus 44.8 to 36.1 for the rehabilitation group. The extent of improvement observed in the surgical cohort proved to be significant when compared with the outcome within the rehabilitation group $(\mathrm{p}=0.045)$. Performance on the shuttle walking test also improved in both groups, but there were no significant differences between the 2 cohorts. There were no statistically significant differences between the 2 groups in any of the secondary outcome measures. Limitations of this study included a $20 \%$ loss to follow-up at 24 months and $28 \%$ crossover from rehabilitation to surgery. The clinical significance of the difference in ODI scores is unclear, especially given the failure to observe a relevant difference in the other outcome measures. Based on these limitations, the study was downgraded to Level II evidence because of lack of benefit of lumbar fusion over intensive rehabilitation.

Ohtori et al. performed a prospective study randomizing patients with discogenic low-back pain into surgical versus nonsurgical treatment groups. ${ }^{26}$ The study consisted of 41 patients with MRI evidence of disc degeneration at either L4-5 or L5-S1 and pain provocation on discography with pain relief with discoblock (a procedure that involves injecting the disc with an anesthetic agent instead of a contrast agent in an effort to eliminate as opposed to reproducing a patient's pain). Surgery consisted of anterior lumbar interbody fusion unless there was presumed to be difficulty with the anterior vessels, in which case a posterolateral instrumented fusion was performed. The nonsurgical control group included daily walking and exercises following 
individual instruction. Outcomes measures included VAS, ODI, and the JOA score. Subjective outcomes were graded according to the North American Spine Society Low Back Outcome Instrument. Radiographic evaluation of fusion was performed with anteroposterior radiographs and CT scan by 3 blinded observers. Data were compared preoperatively and at 1 and 2 years postoperatively.

All of the patients undergoing surgery went on to achieve a solid arthrodesis. Each of the outcomes measures were significantly better for the 2 surgical groups at 2 years as compared with the nonoperative group $(\mathrm{p}<0.05)$. Limitations of the study included a small sample size and inconsistency in the type of surgery performed. This study provides Level II evidence in favor of surgery over walking and exercises in patients with chronic discogenic low-back pain.

Several other recent studies have provided additional data on outcomes of lumbar fusion in patients with chronic low-back pain. ${ }^{2-5,8,10-13,15,18,20-22,24,25,27,28,30,33,34}$ These studies did not have a randomized control group receiving nonoperative treatment. Instead they compared different fusion techniques, compared fusion versus arthroplasty, or failed to include an adequate control group. As a result, they were classified as case series and only provided Level IV evidence supporting the utility of lumbar fusion for the treatment of patients with chronic back pain.

\section{Summary}

The results of this review reveal a lack of sufficient evidence to support a single treatment alternative in patients with intractable low-back pain without stenosis or spondylolisthesis. There is Level II evidence supporting the use of either intensive rehabilitation programs with a cognitive component or lumbar fusion. No significant clinical difference in outcomes were observed between these 2 options, but such rehabilitation programs are not generally available in most areas. There is Level II evidence to support lumbar fusion over traditional physical therapy alone, but that benefit is not present when fusion is compared with a more intensive physical therapy program with cognitive therapy. Numerous case series, constituting Level IV evidence, support the use of lumbar fusion in this patient population. These studies reported significant clinical improvements but failed to incorporate an adequate control group for comparison purposes.

\section{Key Issues for Future Investigation}

Treatment of intractable low-back pain in patients without stenosis or spondylolisthesis remains a difficult problem with many unanswered questions. Further investigation will be necessary to improve the diagnostic capabilities of identifying the origin of pain in this patient population. With improved diagnostic capabilities, intervention can be directed at the primary pathological process.

While there is currently a lack of high-quality Level I evidence to support the use of lumbar fusion for these patients, there are numerous studies that demonstrate a definitive clinical improvement following fusion. Future investigation will be necessary in an attempt to identify factors, both patient specific and surgery related, that are predictive of outcome so that a subset of patients are defined who will respond favorably to fusion as compared with conservative management.

\section{Acknowledgments}

We would like to acknowledge the AANS/CNS Joint Guidelines Committee (JGC) for their review, comments, and suggestions; Laura Mitchell, CNS Guidelines Project Manager, for her organizational assistance; and Linda O'Dwyer, medical librarian, for assistance with the literature searches. We would also like to acknowledge the following individual JGC members for their contributions throughout the review process: Timothy Ryken, M.D.; Kevin Cockroft, M.D.; Sepideh Amin-Hanjani, M.D.; Steven N. Kalkanis, M.D.; John O'Toole, M.D., M.S.; Steven Casha, M.D., Ph.D.; Aaron Filler, M.D., Ph.D., F.R.C.S.; Daniel Hoh, M.D.; Steven Hwang, M.D.; Todd McCall, M.D.; Jeffrey J. Olson, M.D.; Julie Pilitsis, M.D., Ph.D.; Joshua Rosenow, M.D.; and Christopher Winfree, M.D.

\section{Disclosure}

Administrative costs of this project were funded by the Congress of Neurological Surgeons and the Joint Section on Disorders of the Spine and Peripheral Nerves of the American Association of Neurological Surgeons and Congress of Neurological Surgeons. No author received payment or honorarium for time devoted to this project. Dr. Ghogawala receives grants from the Patient Centered Outcomes Research Institute (PCORI) and the National Institutes of Health (NIH). Dr. Groff is a consultant for DePuy Spine and EBI Spine. Dr. Mummaneni owns stock in Spinicity and receives honoraria from DePuy Spine and Globus and royalties from DePuy Spine, Quality Medical Publishers, and Thieme Publishing. Dr. Wang owns stock in Bone Biologics, AxioMed, Amedica, CoreSpine, Expanding Orthopedics, Pioneer, Syndicom, VG Innovations, PearlDiver, Flexuspine, Axis, FzioMed, Benvenue, Promethean, Nexgen, ElectroCore, and Surgitech and holds patents with and receives royalties from Biomet, Stryker, SeaSpine, Aesculap, Osprey, Amedica, Synthes, and Alphatec. The authors report no other potential conflicts of interest concerning the materials or methods used in this study or the findings specified in this paper.

Author contributions to the study and manuscript preparation include the following. Acquisition of data: all authors. Analysis and interpretation of data: all authors. Drafting the article: Eck. Critically revising the article: all authors. Reviewed submitted version of manuscript: all authors. Approved the final version of the manuscript on behalf of all authors: Eck. Study supervision: Kaiser.

\section{References}

1. Abdu WA, Lurie JD, Spratt KF, Tosteson AN, Zhao W, Tosteson TD, et al: Degenerative spondylolisthesis: does fusion method influence outcome? Four-year results of the spine patient outcomes research trial. Spine (Phila Pa 1976) 34:2351-2360, 2009

2. Anderson PA, Schwaegler PE, Cizek D, Leverson G: Work status as a predictor of surgical outcome of discogenic low back pain. Spine (Phila Pa 1976) 31:2510-2515, 2006

3. Arnold PM, Robbins S, Paullus W, Faust S, Holt R, McGuire $\mathrm{R}$ : Clinical outcomes of lumbar degenerative disc disease treated with posterior lumbar interbody fusion allograft spacer: a prospective, multicenter trial with 2-year follow-up. Am J Orthop 38:E115-E122, 2009

4. Aryan HE, Lu DC, Acosta FL Jr, Ames CP: Stand-alone anterior lumbar discectomy and fusion with plate: initial experience. Surg Neurol 68:7-13, 2007

5. Berg S, Tullberg T, Branth B, Olerud C, Tropp H: Total disc replacement compared to lumbar fusion: a randomised controlled trial with 2-year follow-up. Eur Spine J 18:1512-1519, 2009

6. Brox JI, Reikerâs O, Nygaard Ø, Sørensen R, Indahl A, Holm 


\section{Part 7: Fusion for pain without stenosis or spondylolisthesis}

I, et al: Lumbar instrumented fusion compared with cognitive intervention and exercises in patients with chronic back pain after previous surgery for disc herniation: a prospective randomized controlled study. Pain 122:145-155, 2006

7. Brox JI, Sørensen R, Friis A, Nygaard Ø, Indahl A, Keller A, et al: Randomized clinical trial of lumbar instrumented fusion and cognitive intervention and exercises in patients with chronic low back pain and disc degeneration. Spine (Phila Pa 1976) 28:1913-1921, 2003

8. Burkus JK, Gornet MF, Schuler TC, Kleeman TJ, Zdeblick TA: Six-year outcomes of anterior lumbar interbody arthrodesis with use of interbody fusion cages and recombinant human bone morphogenetic protein-2. J Bone Joint Surg Am 91:1181-1189, 2009

9. Chou R, Baisden J, Carragee EJ, Resnick DK, Shaffer WO, Loeser JD: Surgery for low back pain: a review of the evidence for an American Pain Society Clinical Practice Guideline. Spine (Phila Pa 1976) 34:1094-1109, 2009

10. Dawson E, Bae HW, Burkus JK, Stambough JL, Glassman SD: Recombinant human bone morphogenetic protein-2 on an absorbable collagen sponge with an osteoconductive bulking agent in posterolateral arthrodesis with instrumentation. A prospective randomized trial. J Bone Joint Surg Am 91:1604-1613, 2009

11. Delamarter R, Zigler JE, Balderston RA, Cammisa FP, Goldstein JA, Spivak JM: Prospective, randomized, multicenter Food and Drug Administration investigational device exemption study of the ProDisc-L total disc replacement compared with circumferential arthrodesis for the treatment of twolevel lumbar degenerative disc disease: results at twenty-four months. J Bone Joint Surg Am 93:705-715, 2011

12. Deutsch H, Musacchio MJ Jr: Minimally invasive transforaminal lumbar interbody fusion with unilateral pedicle screw fixation. Neurosurg Focus 20(3):E10, 2006

13. Esposito P, Pinheiro-Franco JL, Froelich S, Maitrot D: Predictive value of MRI vertebral end-plate signal changes (Modic) on outcome of surgically treated degenerative disc disease. Results of a cohort study including 60 patients. Neurochirurgie 52:315-322, 2006

14. Fairbank J, Frost H, Wilson-MacDonald J, Yu LM, Barker $\mathrm{K}$, Collins R, et al: Randomised controlled trial to compare surgical stabilization of the lumbar spine with an intensive rehabilitation programme for patients with chronic low back pain: the MRC spine stabilisation trial. BMJ 330:1233, 2005 (Erratum in BMJ 330:1485, 2005)

15. Fogel GR, Toohey JS, Neidre A, Brantigan JW: Is one cage enough in posterior lumbar interbody fusion: a comparison of unilateral single cage interbody fusion to bilateral cages. J Spinal Disord Tech 20:60-65, 2007

16. Fritzell P, Hägg O, Wessberg P, Nordwall A, Swedish Lumbar Spine Study Group: 2001 Volvo Award Winner in Clinical Studies. Lumbar fusion versus nonsurgical treatment for chronic low back pain: a multicenter randomized controlled trial from the Swedish Lumbar Spine Study Group. Spine (Phila Pa 1976) 26:2521-2532, 2001

17. Frost H, Lamb SE, Shackleton CH: A functional restoration programme for chronic low back pain: a prospective outcome study. Physiotherapy 86:285-293, 2000

18. Gepstein R, Shabat S, Reichel M, Pikarsky I, Folman Y: Treatment of postdiscectomy low back pain by percutaneous posterior lumbar interbody fusion versus open posterior lumbar fusion with pedicle screws. Spine J 8:741-746, 2008

19. Gibson JN, Waddell G: Surgery for degenerative lumbar spondylosis: updated Cochrane Review. Spine (Phila Pa 1976) 30:2312-2320, 2005

20. Glassman SD, Carreon LY, Djurasovic M, Dimar JR, Johnson JR, Puno RM, et al: Lumbar fusion outcomes stratified by specific diagnostic indication. Spine J 9:13-21, 2009

21. Gornet MF, Burkus JK, Dryer RF, Peloza JH: Lumbar disc arthroplasty with Maverick disc versus stand-alone interbody fusion: a prospective, randomized, controlled, multicenter investigational device exemption trial. Spine (Phila Pa 1976) 36:E1600-E1611, 2011

22. Guyer RD, McAfee PC, Banco RJ, Bitan FD, Cappuccino A, Geisler FH, et al: Prospective, randomized, multicenter Food and Drug Administration investigational device exemption study of lumbar total disc replacement with the CHARITE artificial disc versus lumbar fusion: five-year follow-up. Spine J 9:374-386, 2009

23. Hägg O, Fritzell P, Odén A, Nordwall A, Swedish Lumbar Spine Study Group: Simplifying outcome measurement: evaluation of instruments for measuring outcome after fusion surgery for chronic low back pain. Spine (Phila Pa 1976) 27:1213-1222, 2002

24. Niemeyer T, Halm H, Hackenberg L, Liljenqvist U, Bövingloh AS: Post-discectomy syndrome treated with lumbar interbody fusion. Int Orthop 30:163-166, 2006

25. Ohtori S, Koshi T, Yamashita M, Takaso M, Yamauchi K, Inoue G, et al: Single-level instrumented posterolateral fusion versus non-instrumented anterior interbody fusion for lumbar spondylolisthesis: a prospective study with a 2-year follow-up. J Orthop Sci 16:352-358, 2011

26. Ohtori S, Koshi T, Yamashita M, Yamauchi K, Inoue G, Suzuki M, et al: Surgical versus nonsurgical treatment of selected patients with discogenic low back pain: a small-sized randomized trial. Spine (Phila Pa 1976) 36:347-354, 2011

27. Peng B, Chen J, Kuang Z, Li D, Pang X, Zhang X: Diagnosis and surgical treatment of back pain originating from endplate. Eur Spine J 18:1035-1040, 2009

28. Rapan S, Jovanović S, Gulan G: Transforaminal lumbar interbody fusion (TLIF) and unilateral transpedicular fixation. Coll Antropol 34:531-534, 2010

29. Resnick DK, Choudhri TF, Dailey AT, Groff MW, Khoo L, Matz PG, et al: Guidelines for the performance of fusion procedures for degenerative disease of the lumbar spine. Part 7: intractable low-back pain without stenosis or spondylolisthesis. J Neurosurg Spine 2:670-672, 2005

30. Suratwala SJ, Pinto MR, Gilbert TJ, Winter RB, Wroblewski JM: Functional and radiological outcomes of 360 degrees fusion of three or more motion levels in the lumbar spine for degenerative disc disease. Spine (Phila Pa 1976) 34:E351E358, 2009

31. Taylor S, Frost H, Taylor A, Barker K: Reliability and responsiveness of the shuttle walking test in patients with chronic low back pain. Physiother Res Int 6:170-178, 2001

32. Weinstein JN, Lurie JD, Tosteson TD, Hanscom B, Tosteson AN, Blood EA, et al: Surgical versus nonsurgical treatment for lumbar degenerative spondylolisthesis. N Engl J Med 356:2257-2270, 2007

33. Zhou ZJ, Zhao FD, Fang XQ, Zhao X, Fan SW: Meta-analysis of instrumented posterior interbody fusion versus instrumented posterolateral fusion in the lumbar spine. A review. J Neurosurg Spine 15:295-310, 2011

34. Zigler J, Delamarter R, Spivak JM, Linovitz RJ, Danielson GO III, Haider TT, et al: Results of the prospective, randomized, multicenter, Food and Drug Administration investigational device exemption study of the ProDisc-L total disc replacement versus circumferential fusion for the treatment of 1-level degenerative disc disease. Spine (Phila Pa 1976) 32:1155-1163, 2007

Manuscript submitted March 13, 2014.

Accepted April 4, 2014.

Please include this information when citing this paper: DOI: 10.3171/2014.4.SPINE14270.

Address correspondence to: Michael G. Kaiser, M.D., Columbia University, Neurological Surgery, The Neurological Institute, 710 W. 168th St., New York, NY 10032. email: mgk7@columbia.edu. 